\title{
Effects of inhaled nitric oxide on regional blood flow are consistent with intravascular nitric oxide delivery
}

\author{
Richard O. Cannon III, ${ }^{1}$ Alan N. Schechter, ${ }^{2}$ Julio A. Panza, ${ }^{1}$ Frederick P. Ognibene, ${ }^{3}$ \\ Margaret E. Pease-Fye, ${ }^{3}$ Myron A. Waclawiw, ${ }^{4}$ James H. Shelhamer, ${ }^{3}$ \\ and Mark T. Gladwin ${ }^{2,3}$ \\ ${ }^{1}$ Cardiology Branch, National Heart, Lung, and Blood Institute, \\ ${ }^{2}$ Laboratory of Chemical Biology, National Institute of Diabetes, Digestive, and Kidney Diseases, \\ ${ }^{3}$ Critical Care Medicine Department, Clinical Center, and \\ ${ }^{4}$ Office of Biostatistics Research, National Heart, Lung, and Blood Institute, NIH, Bethesda, Maryland, USA
}

Address correspondence to: Richard O. Cannon III, National Institutes of Health, Building 10,

Room 7B-15, 10 Center Drive, MSC 1650, Bethesda, Maryland 20892-1650, USA.

Phone: (301) 496-9895; Fax: (301) 402-0888; E-mail: cannonr@nih.gov.

Received for publication March 16, 2001, and accepted in revised form May 24, 2001.

\begin{abstract}
Nitric oxide (NO) may be stabilized by binding to hemoglobin, by nitrosating thiol-containing plasma molecules, or by conversion to nitrite, all reactions potentially preserving its bioactivity in blood. Here we examined the contribution of blood-transported NO to regional vascular tone in humans before and during NO inhalation. While breathing room air and then room air with NO at 80 parts per million, forearm blood flow was measured in 16 subjects at rest and after blockade of forearm NO synthesis with $\mathrm{N}^{\mathrm{G}}$-monomethyl-L-arginine (L-NMMA) followed by forearm exercise stress. L-NMMA reduced blood flow by $25 \%$ and increased resistance by $50 \%$, an effect that was blocked by NO inhalation. With NO inhalation, resistance was significantly lower during L-NMMA infusion, both at rest and during repetitive hand-grip exercise. S-nitrosohemoglobin and plasma S-nitrosothiols did not change with NO inhalation. Arterial nitrite levels increased by $11 \%$ and arterial nitrosyl(heme)hemoglobin levels increased tenfold to the micromolar range, and both measures were consistently higher in the arterial than in venous blood. S-nitrosohemoglobin levels were in the nanomolar range, with no significant artery-to-vein gradients. These results indicate that inhaled NO during blockade of regional NO synthesis can supply intravascular NO to maintain normal vascular function. This effect may have application for the treatment of diseases characterized by endothelial dysfunction.
\end{abstract}

J. Clin. Invest. 108:279-287 (2001). DOI:10.1172/JCI200112761.

\section{Introduction}

Nitric oxide (NO) is a soluble gas that is continuously synthesized in endothelial cells from the amino acid Larginine by the constitutive calcium and calmodulindependent enzyme NO synthase and is a critical endogenous vasodilator (1-4). The importance of endothelium-derived NO in the regulation of coronary and systemic vasodilator tone has been demonstrated experimentally by inhibiting its regional synthesis. Thus, $\mathrm{N}^{\mathrm{G}}$-monomethyl-L-arginine (L-NMMA), which competes with $\mathrm{L}$-arginine as the substrate for $\mathrm{NO}$ synthase but cannot be oxidized to form $\mathrm{NO}$ (5), decreases coronary and systemic blood flow when infused intraarterially into regional vascular beds (6-9). Considerable recent interest and controversy have focused on the role of intravascular NO-derived molecules that conserve and stabilize NO bioactivity and may contribute to blood flow and oxygen delivery. Such molecules include plasma low- and high-molecular-weight S-nitrosothiols and nitrite $(10,11)$. In addition, NO reacts reversibly with hemoglobin to form an NO-heme adduct, nitrosyl(heme)hemoglobin, and can also nitrosate a surface thiol on cysteine-93 of the $\beta$-globin chain to form S- nitrosohemoglobin (SNO-Hb). The role of hemoglobin as an $\mathrm{NO}$ transporter is particularly appealing in that delivery of NO may be linked energetically to oxygen binding, promoting the allosteric delivery of oxygen and NO to regions with low oxygen tension (12-15).

The role of intravascular NO species in the regulation of vascular tone is supported by studies of NO breathing. Despite conventional wisdom that NO immediately reacts, with near-diffusion limited kinetics, with oxyhemoglobin to form bioinactive nitrate, animal studies have shown that NO breathing reduces systemic vascular resistance (16), increases kidney filtration rates (17), increases aortic cyclic guanosine monophosphate levels (18), and restores blood flow to the intestine after infusion of a NO synthase inhibitor $(19,20)$. While these observations are consistent with intravascular biostabilization, transport, and delivery of NO, the mechanism of such delivery and the relevance to human physiology and therapeutics is unknown. We therefore sought to determine whether NO inhalation augments NO transport in blood and increases blood flow in a regional vascular bed distant from the lungs. We hypothesized that NO synthesis 
within the forearm endothelium would be sufficient to maintain resting vascular tone, and thus NO delivery from blood might be more readily appreciated during regional inhibition of NO synthesis, pharmacologically mimicking endothelial dysfunction. To determine how NO is stabilized and delivered to the peripheral vasculature, we measured all known bioactive NO species, including low- and high-molecular-weight plasma S-nitrosothiols, SNO-Hb, nitrosyl(heme)hemoglobin, and plasma nitrite.

\section{Methods}

The protocol was approved by the Institutional Review Board of the National Heart, Lung and Blood Institute, and informed consent was obtained from all volunteer subjects. Eight men and eight women, with an average age of 33 years (range 21-59 years), participated in the study. Volunteers had a normal hemoglobin concentration, and all were in excellent general health without risk factors for endothelial dysfunction (smoking, fasting blood sugar greater than $120 \mathrm{mg} / \mathrm{dl}$, LDL cholesterol greater than $130 \mathrm{mg} / \mathrm{dL}$, blood pressure greater than $140 / 80 \mathrm{mmHg}$ ). Subjects were placed on a nitraterestricted diet ( $<15 \mathrm{mg} /$ day) for 3 days before the study and fasted, except for water, after midnight of the study day and during the study (diet described at www.nhlbi.nih.gov/labs/7east/lowNdiet.htm).

Forearm blood flow measurements. Brachial artery and antecubital vein catheters were placed in the arm, with the intra-arterial catheter connected to a pressure transducer for blood pressure measurements and an infusion pump delivering $5 \%$ dextrose in water at $0.5 \mathrm{ml} / \mathrm{min}$. After 20 minutes of rest, baseline arterial and venous blood samples were obtained, and forearm blood flow measurements were made by strain gauge venous-occlusion plethysmography, as reported previously (8). A series of seven blood flow measurements were averaged for each blood flow determination. Forearm vascular resistance was determined by dividing mean blood pressure by forearm blood flow values. Intra-arterial LNMMA at $8 \mu \mathrm{mol} / \mathrm{min}$ then replaced $5 \%$ dextrose in water at the same infusion rate of $0.5 \mathrm{ml} / \mathrm{min}$. This dosage was chosen because of our previous demonstration that vascular effects of L-NMMA in humans are reproducible at this dosage when infusions are separated in time by approximately 1 hour (11). After 5 minutes of intra-arterial L-NMMA, arterial and venous blood samples were obtained and forearm blood flow was measured. Forearm exercise was then initiated during continued L-NMMA infusion, using a hand-grip dynamometer, with one-third of the previously determined maximum grip strength sustained for $10 \mathrm{sec}-$ onds followed by relaxation for 5 seconds, in repetitive cycles. After 5 minutes of exercise, arterial and venous blood samples were obtained and forearm blood flow was measured during continued exercise. Five percent dextrose in water then replaced L-NMMA infusion into the brachial artery. Inhaled $\mathrm{NO}$ was then delivered at 80 ppm by an anesthesia face mask with a reservoir bag
(INO Therapeutics Inc., Clinton, New Jersey, USA), with continuous monitoring to assure oxygen delivery of $21 \%$, as reported previously $(15,21)$. After 1 hour of NO inhalation, arterial and venous samples and blood flow measurements were obtained as described previously for the measurements on room air.

Arterial and venous $\mathrm{pH}, \mathrm{pO}_{2}$, and $\mathrm{pCO}_{2}$ were measured at the bedside using the i-STAT system (i-STAT Corp., East Windsor, New Jersey, USA).

Methemoglobin concentration. Methemoglobin concentrations were measured by absorption spectroscopy at 700, 630, 576, and $560 \mathrm{~nm}$ using the Winterbourn relationship (22).

Hemoglobin preparation and ozone-based chemiluminescent detection of nitrosyl(beme)hemoglobin and S-nitrosobemoglobin. After measurement of methemoglobin concentration, pelleted red cell samples were lysed in distilled water with $0.5 \mathrm{mM}$ EDTA (1:2 dilution), and $200 \mu \mathrm{l}$ of the hemoglobin lysate was added to $600 \mu \mathrm{l}$ of $0.2 \mathrm{M} \mathrm{KCN} / 0.2 \mathrm{M} \mathrm{K}_{3} \mathrm{Fe}^{\mathrm{III}}(\mathrm{CN})_{6}$ with $0.5 \mathrm{mM}$ EDTA in PBS or to $600 \mu \mathrm{l}$ of PBS with $0.5 \mathrm{mM}$ EDTA and incubated for 35 minutes. Treatment with 100 -fold molar excess of $\mathrm{KCN}$ and $\mathrm{K}_{3} \mathrm{Fe}(\mathrm{CN})_{6}$ selectively removes NO from heme while preserving the $\mathrm{S}$ nitrosothiol bond (15). After the 35-minute incubation, $500 \mu \mathrm{l}$ of the hemoglobin sample was passed
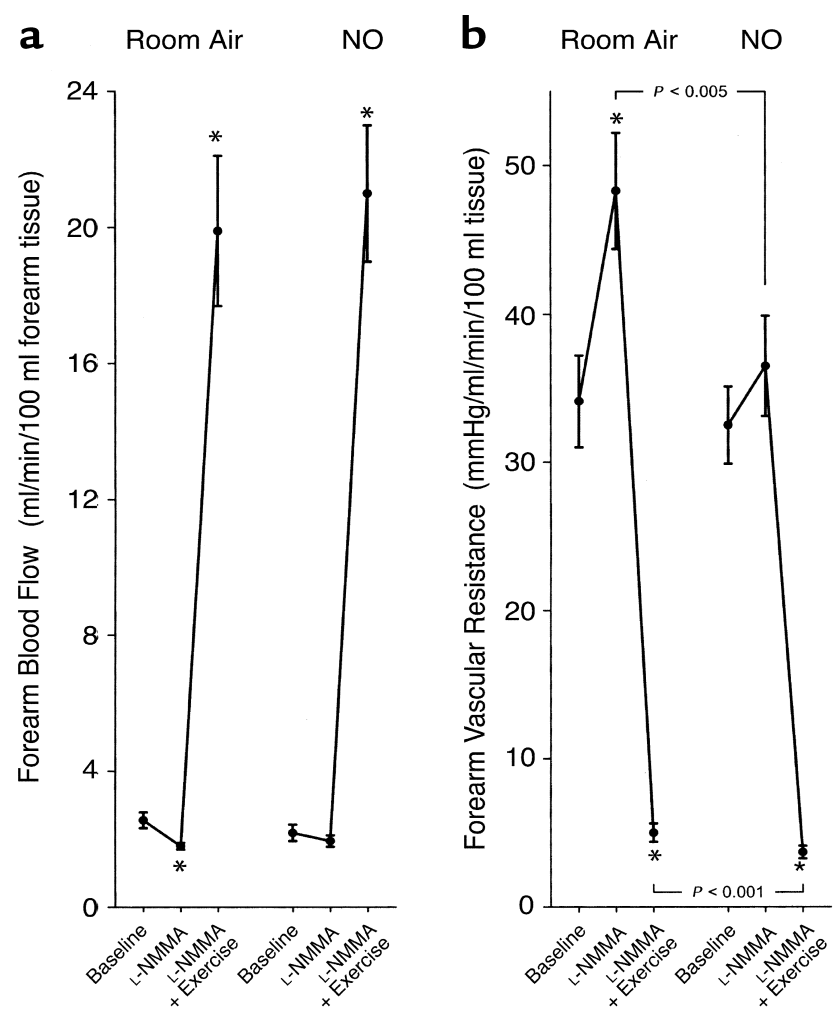

\section{Figure 1}

Forearm blood flow (a) and vascular resistance $(\mathbf{b})$ at baseline and during intra-arterial infusion of L-NMMA (to inhibit forearm NO synthesis), followed by forearm exercise. Initial measurements were made on room air, then repeated during $\mathrm{NO}$ breathing at $80 \mathrm{ppm}$. Data are mean \pm SEM. ${ }^{*} P<0.001$ compared with baseline. 

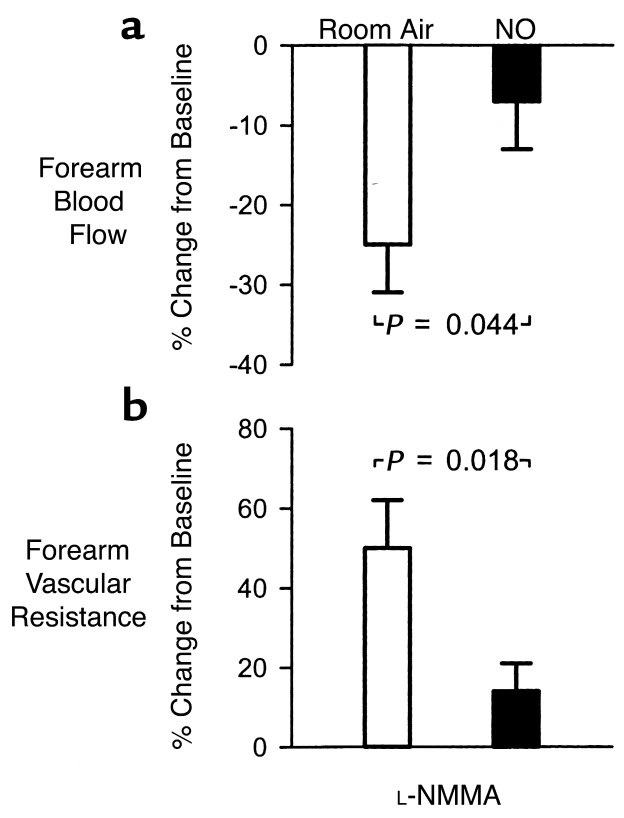

through an extensively washed (2-hour wash with 0.5 mM EDTA HPLC-grade water to remove column preservatives), $9.5-\mathrm{ml}$ bed volume Sephadex G25 column (17-0852-02; Amersham Pharmacia, Uppsala, Sweden) to remove nitrite, small thiols, and the KCN/ $\mathrm{K}_{3} \mathrm{Fe}^{\mathrm{III}}(\mathrm{CN})_{6}$. The hemoglobin concentration of the Sephadex G25 effluent was measured by conversion to cyanomethemoglobin. Hemoglobin samples (200 $\mu \mathrm{l})$ were reacted with $\mathrm{I}_{3}{ }^{-}$to release NO for chemiluminescent detection (15). The method for the measurement of nitrite and S-nitrosothiols by reaction with $\mathrm{I}_{3}{ }^{-}$to release $\mathrm{NO}$ gas $(21,23)$ was applied to hemoglobin that had been treated with and without KCN and $\mathrm{K}_{3} \mathrm{Fe}^{\mathrm{III}}(\mathrm{CN})_{6}$. In brief, $7 \mathrm{ml}$ of glacial acetic acid and 2 $\mathrm{ml}$ of distilled water were mixed with $50 \mathrm{mg}$ of KI. A crystal of $\mathrm{I}_{2}$ was added to yield a concentration of 6-20 mM.(23). Helium was bubbled through the reaction mixture, then through $1 \mathrm{~N} \mathrm{NaOH}$, and then into the Sievers Model $280 \mathrm{NO}$ analyzer $(15,21)$. The total amount of SNO-Hb plus nitrosyl(heme)hemoglobin was determined by directly adding hemoglobin samples to the $\mathrm{I}_{3}{ }^{-}$solution without pretreatment with $\mathrm{KCN} / \mathrm{K}_{3} \mathrm{Fe}^{\mathrm{III}}(\mathrm{CN})_{6}$. The background NO signal from water collected from the washed G25 Sephadex column was subtracted from this signal.

SNO-Hb could be determined by first pretreating hemoglobin samples with $\mathrm{KCN} / \mathrm{K}_{3} \mathrm{Fe}^{\mathrm{III}}(\mathrm{CN})_{6}$, which preserves $\mathrm{SNO}-\mathrm{Hb}$ but removes NO from heme (15), before addition to the $\mathrm{I}_{3}{ }^{-}$solution. The quantity of nitrosyl(heme)hemoglobin is therefore the difference in amount of total SNO-Hb plus nitrosyl(heme)hemoglobin, determined without pretreatment of $\mathrm{KCN} /$ $\mathrm{K}_{3} \mathrm{Fe}^{\mathrm{III}}(\mathrm{CN})_{6}$, and $\mathrm{SNO}-\mathrm{Hb}$ determined with $\mathrm{KCN} /$ $\mathrm{K}_{3} \mathrm{Fe}^{\mathrm{III}}(\mathrm{CN})_{6}$ pretreatment. This value was divided by the concentration of the hemoglobin, and the total expressed as concentration in whole blood.
Ozone-based chemiluminescent determination of serum nitrate, nitrite, and high-and low-molecular-weight S-nitrosothiols. Blood samples were drawn into EDTA collection tubes and centrifuged at $750 \mathrm{~g}$ for 5 minutes. Plasma aliquots were removed and stored at $-80^{\circ} \mathrm{C}$ until assayed for nitrate, nitrite, and low-molecular-weight S-nitrosothiols (LMW-SNO). These plasma samples were later thawed, diluted $1: 2$ in 0.5 mM EDTA water, and filtered through prewashed (four times with nitrite-free water) 30,000 molecular-weight cut-off filtration units. Samples were then injected in different reductants in-line with the Sievers Model $280 \mathrm{NO}$ analyzer. Nitrite was measured by reduction in acidified KI ( $7 \mathrm{ml}$ of glacial acetic acid, $2 \mathrm{ml}$ of distilled water, $50 \mathrm{mg}$ of KI) (23). Nitrate was measured by reduction in vanadium (III) at $90^{\circ} \mathrm{C}$ (24). LMW-SNO was measured in $\mathrm{Cu}^{+} / \mathrm{L}-$ cysteine, which does not release NO from nitrate or nitrite (25). There is an approximately $25 \%$ loss of LMW-SNO in plasma over 30 minutes, even in the presence of $0.5 \mathrm{mM}$ EDTA, resulting in a measured limit of sensitivity of the $\mathrm{Cu}^{+} / \mathrm{L}$-cysteine-chemiluminescent assay for S-nitrothiols in plasma of $25 \mathrm{nM}$. (Because LMW-SNO was not detectable by our assay, we can conclude that the levels of LMW-SNO in human plasma are less than $25 \mathrm{nM}$.)

Because high-molecular-weight S-nitrosothiols (HMW-SNO) are unstable in plasma, we immediately analyzed plasma for this NO species. A $500-\mu \mathrm{l}$ aliquot of the unfrozen plasma was run on a $9.5-\mathrm{ml}$ bed volume Sephadex G25 sizing column in a dark room within 30 minutes of specimen collection. The $3-$ to $3.5-\mathrm{ml}$ elution volume containing plasma high-molecularweight proteins (albumin and immunoglobulins) was collected, and $200 \mu \mathrm{l}$ was reacted in $\mathrm{I}_{3}^{-}$. Injection of samples into this $\mathrm{I}_{3}{ }^{-}$reductant stoichiometrically produces NO from nitrosothiols $(21,23)$. 


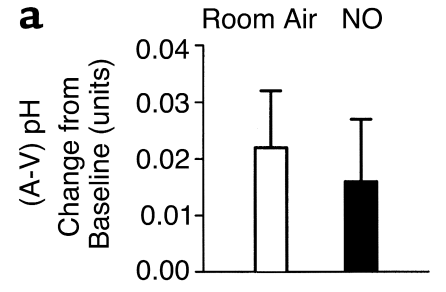

b

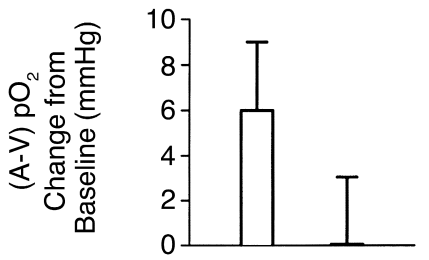

c

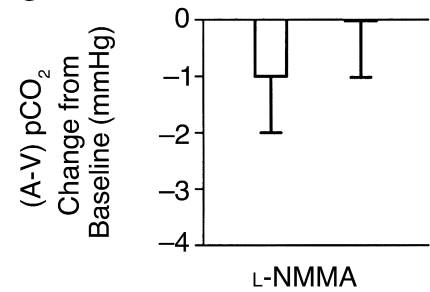

Room Air $\mathrm{NO}$
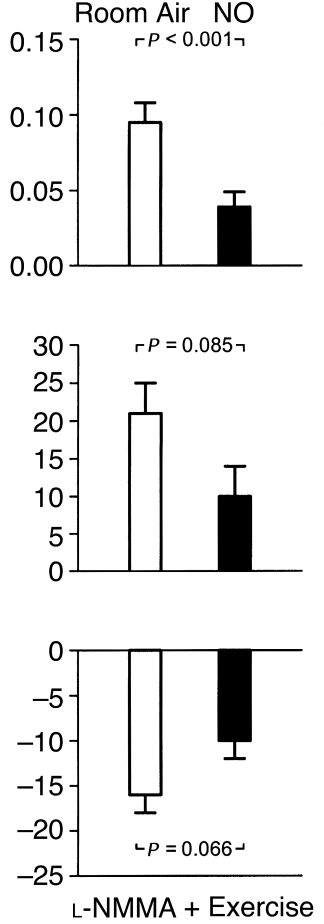

Figure 3

Forearm artery-to-vein $(\mathrm{A}-\mathrm{V})$ differences in $\mathrm{pH}(\mathbf{a}), \mathrm{pO}_{2}(\mathbf{b})$, and $\mathrm{PCO}_{2}(\mathbf{c})$ expressed as change from baseline during intra-arterial infusion of L-NMMA (left column), followed by forearm exercise (right column). Initial measurements were made on room air, then repeated during NO breathing at $80 \mathrm{ppm}$. Data are mean \pm SEM.

Statistical analysis. An a priori sample-size calculation determined that 16 subjects would be necessary for the study to detect a $25 \%$ improvement in forearm blood flow during $\mathrm{NO}$ inhalation when forearm NO synthesis had been inhibited by L-NMMA compared with room air values $($ alpha $=0.05$, power $=0.80)$. Two-sided $P$ values were calculated by paired $t$ test for the pairwise comparisons between baseline and L-NMMA infusion values, between baseline and exercise values, and between room air and NO inhalation values at comparable time points of the study. Repeat measures ANOVA was performed for artery-to-vein gradients of NO species during basal, L-NMMA infusion, and exercise conditions. Measurements shown are mean \pm SEM.

\section{Results}

Forearm bemodynamics. L-NMMA infusion during room air breathing significantly reduced forearm blood flow (Figures $1 \mathrm{a}$ and Figure $2 \mathrm{a}$ ) and increased forearm vascular resistance (Figures $1 \mathrm{~b}$ and Figure $2 \mathrm{~b}$ ) from baseline values (both $P<0.001)$. This vasoconstrictor response to L-NMMA was associated with significant increases in the forearm artery-to-vein partial pressure of oxygen $\left(\mathrm{pO}_{2}\right)$ gradient (from $59 \pm 4$ to $64 \pm 4 \mathrm{mmHg}$; $P=0.044$ ) and artery-to-vein $\mathrm{pH}$ gradient (from 0.029 \pm 0.008 to $0.051 \pm 0.010$ units; $P=0.031)$ due to reduction in venous $\mathrm{pO}_{2}$ (from $41 \pm 4$ to $35 \pm 3 \mathrm{mmHg} ; P=$

0.014 ) and $\mathrm{pH}$ (from $7.353 \pm 0.008$ to $7.338 \pm 0.008$ units; $P=0.084$ ) levels from baseline (Figure 3 ). After 5 minutes of repetitive hand-grip exercise during continued L-NMMA infusion, blood flow increased nearly eightfold (Figure $1 \mathrm{a}$ and Figure $2 \mathrm{c}$ ) and resistance declined (Figure $1 \mathrm{~b}$ and Figure $2 \mathrm{~d}$ ) from baseline values (both $P<0.001)$. This response was associated with further widening of the artery-to-vein $\mathrm{pO}_{2}$ gradient (to $79 \pm 2 \mathrm{mmHg} ; P<0.001$ ) and $\mathrm{pH}$ gradient (to $0.124 \pm$ 0.012 units; $P<0.001$ ) from baseline due to significant reduction in venous $\mathrm{pO}_{2}$ (to $24 \pm 1 \mathrm{mmHg} ; P<0.001$ ) and $\mathrm{pH}$ (to $7.263 \pm 0.011$ units; $P<0.001$ ) levels during exercise (Figure 3 ).

After termination of exercise, L-NMMA infusion was discontinued, $5 \%$ dextrose in water was resumed, and inhalation of NO was initiated. After 1 hour of inhalation, mean blood pressure tended to increase (from 80 to $85 \mathrm{mmHg}$; $P=0.067$ ) compared with baseline measurements on room air. NO inhalation did not significantly alter blood flow from baseline room air values $(2.19 \pm 0.24$ vs. $2.56 \pm 0.23 \mathrm{ml} / \mathrm{min}$ per $100 \mathrm{ml}$ forearm tissue, $P=0.083)$, and resistance values were similar $(32.5 \pm 3.6$ vs. $34.1 \pm 3.1 \mathrm{mmHg} / \mathrm{ml} / \mathrm{min}$ per $100 \mathrm{ml}$ forearm tissue; $P=0.652)$. The $\mathrm{pO}_{2}$ levels in the artery (92 \pm 2 vs. $100 \pm 2 \mathrm{mmHg} ; P=0.001)$ and vein $(27 \pm 2$ vs. $41 \pm 4 \mathrm{mmHg} ; P=0.002)$ were significantly reduced during $\mathrm{NO}$ breathing compared with room air values, with a nonsignificant increase in the artery-to-vein $\mathrm{pO}_{2}$ gradient $(66 \pm 3$ vs. $59 \pm 4 \mathrm{mmHg} P=0.115)$. NO breathing did not change arterial $\mathrm{pH}(7.383 \pm 0.007$ vs. $7.382 \pm 0.005$ units; $P=0.910)$, venous $\mathrm{pH}(7.343 \pm$ 0.007 vs. $7.353 \pm 0.008$ units; $P=0.151)$ or the artery-tovein $\mathrm{pH}$ gradient $(0.039 \pm 0.009$ vs. $0.029 \pm 0.008$ units; $P=0.272)$ compared with room air baseline values. These results are consistent with minimal effects of inhaled NO on basal blood flow in the arm, but an increase in pulmonary blood shunting.

While there was minimal effect of NO inhalation on baseline blood flow, the L-NMMA-induced decrease in blood flow (Figure 1a and Figure $2 \mathrm{a}$ ) and increase in resistance (Figure $1 \mathrm{~b}$ and Figure $2 \mathrm{~b}$ ) measured during room air breathing were prevented by inhaled NO during reinfusion of L-NMMA, resulting in lower absolute resistance (Figure $1 \mathrm{~b}$ ). In contrast to the effect of $\mathrm{L}_{\text {- }}$ NMMA during room air breathing, there was no effect of L-NMMA on artery-to-vein $\mathrm{pO}_{2}$ gradients (from 66 \pm 3 to $66 \pm 4 \mathrm{mmHg} ; P=0.889)$ and artery-to-vein $\mathrm{pH}$ gradients (from $0.039 \pm 0.009$ to $0.057 \pm 0.009$ units; $P=0.132$ ) compared with the baseline values after 1 hour of NO breathing.

During repetitive hand-grip exercise with continuation of intra-arterial L-NMMA infusion and NO inhalation, blood flow tended to increase to a greater extent from the preceding baseline compared with the blood flow response on room air (Figure 2c). The percentage of change (decrease) in forearm vascular resistance with exercise during NO inhalation was significantly greater than the decrease in resistance on room air (Figure $2 \mathrm{~d}$ ) and resulted in significantly lower absolute resistance 

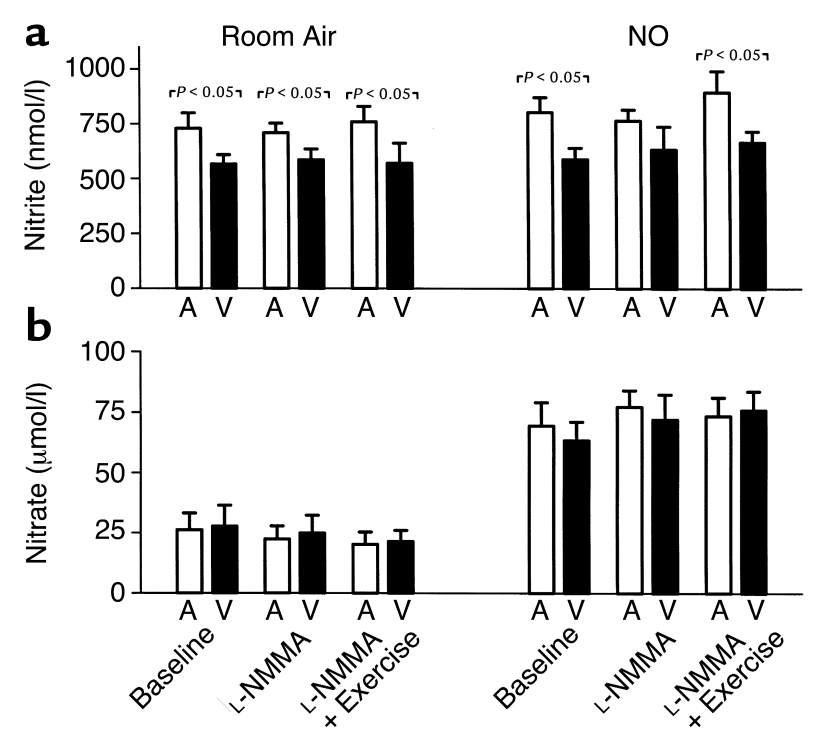

Figure 4

Arterial $(A)$ and venous $(V)$ plasma levels of nitrite $(\mathbf{a})$ and nitrate (b) at baseline and during infusion of L-NMMA, followed by forearm exercise. Initial measurements were made on room air, then repeated during NO breathing at $80 \mathrm{ppm}$. Data are mean \pm SEM.

(Figure 1b). This increase in blood flow during NO inhalation resulted in metabolic evidence of increased oxygen delivery: The artery-to-vein $\mathrm{pO}_{2}$ gradient $(76 \pm$ 2 vs. $79 \pm 2 \mathrm{mmHg} ; P=0.162)$ and $\mathrm{pCO}_{2}$ gradient $(-14$ \pm 2 vs. $-18 \pm 2 \mathrm{mmHg} ; P=0.096)$ during exercise with LNMMA infusion and NO inhalation tended to be less than room air exercise values, with significantly lower venous $\mathrm{PCO}_{2}(54 \pm 2$ vs. $58 \pm 2 \mathrm{mmHg} ; P=0.049)$ compared with room air exercise values. The artery-to-vein $\mathrm{pH}$ gradient during exercise and $\mathrm{NO}$ inhalation was significantly less than room air exercise values $(0.078 \pm$ 0.015 vs. $0.124 \pm 0.012$ units, $P<0.001)$ due to significantly higher venous $\mathrm{pH}$ during $\mathrm{NO}$ breathing $(7.289 \pm$ 0.012 vs. $7.263 \pm 0.011$ units; $P=0.013$ ) (Figure 3 ).

NO species in blood. Consistent with the high affinity of NO for the heme groups of hemoglobin and the preponderance of oxyhemoglobin in the pulmonary circulation, the primary reaction products during $\mathrm{NO}$ inhalation were methemoglobin and nitrate (the byproducts of the reaction of NO and oxyhemoglobin). Nitrate levels increased almost fourfold during NO breathing $(P<0.001)$, but without significant arteryto-vein gradients (Figure 4b). Methemoglobin levels, converted to micromolar concentrations, were similar to the nitrate concentrations: during room air breathing, levels were $18.8 \pm 2.4 \mu \mathrm{M}, 18.8 \pm 2.4 \mu \mathrm{M}$, and 18.1 $\pm 2.3 \mu \mathrm{M}$ at baseline during L-NMMA infusion and subsequent exercise, respectively. During NO breathing, levels were $106.3 \pm 9.9 \mu \mathrm{M}, 112.5 \pm 10.0 \mu \mathrm{M}$, and $121.9 \pm 10.1 \mu \mathrm{M}$ at baseline, during L-NMMA infusion, and subsequent exercise, respectively.

Forearm artery-to-vein gradients during room air breathing were present for plasma nitrite $(P<0.001$ by ANOVA; Figure $4 a$ ) but not plasma nitrate (Figure $4 b$ ), consistent with our previous studies (11). During NO breathing, arterial nitrite levels increased by $11 \%$ to $868 \pm$ $59 \mathrm{nM}(P=0.03)$, with artery-to-vein gradients observed during all phases of the study $(P<0.001$ by ANOVA).

Baseline HMW-SNO levels, measured immediately upon sample collection in nine of the study subjects, were nonsignificantly higher in the venous plasma than the arterial plasma ( $35 \pm 13$ vs. $24 \pm 9 \mathrm{nM}$, respectively; $P=0.39)$ and did not significantly increase in venous (37 $\pm 13 \mathrm{nM} ; P=0.74))$ or arterial $(28 \pm 10 \mathrm{nM} ; P=0.85)$ plasma with NO inhalation. Plasma LMW-SNO were not detected either at baseline or during NO breathing.

We have reported previously that baseline arterial levels of SNO-Hb and nitrosyl(heme)hemoglobin in humans are $161 \pm 42 \mathrm{nM}$ and $150 \pm 80 \mathrm{nM}$, respectively, with no significant artery-to-vein gradients $(11,15)$. In this study, these species were measured only during NO breathing to allow for immediate measurement without sample freezing (Figure 5, a and b). SNO-Hb levels during NO breathing were not significantly different from the previously reported basal levels, and while trends toward artery-to-vein gradients were measured, these did not achieve statistical significance (Figure 5a). In contrast, nitrosyl(heme)-hemoglobin levels during NO breathing rose approximately tenfold, compared with levels determined previously by us in human subjects breathing room air (15), to $860 \pm 118 \mathrm{nM}(P<0.001$ by nonpaired two-sided $t$ test), and the arterial levels
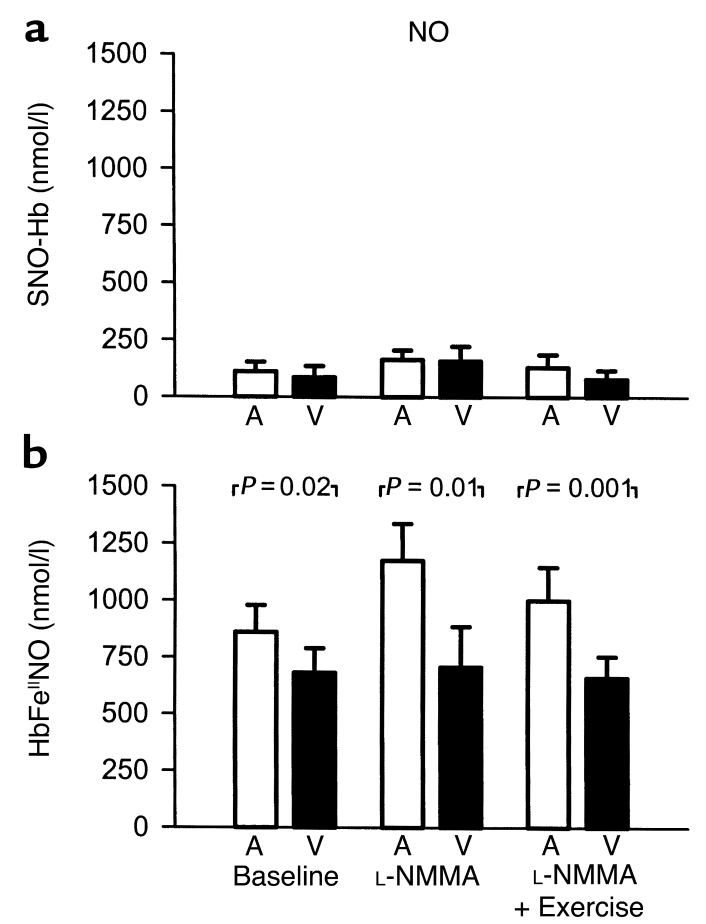

Figure 5

Arterial (A) and venous (V) levels of red cell S-nitrosohemoglobin (SNO-Hb) (a) and nitrosyl(heme)hemoglobin (HbFe"NO) (b) measured during $\mathrm{NO}$ breathing at $80 \mathrm{ppm}$ at baseline and during infusion of L-NMMA, followed by forearm exercise. Data are mean \pm SEM. 
of nitrosyl(heme)-hemoglobin were consistently higher than venous levels during $\mathrm{NO}$ breathing at rest, during L-NMMA infusion, and during exercise $(P<0.001$ by ANOVA; Figure $5 b)$.

\section{Discussion}

NO inhalation has been shown to reduce pulmonary vascular resistance in experimental models of lung injury and to improve pulmonary hypertension and gas exchange in patients after heart surgery and with acute respiratory distress syndrome (26-29). These and numerous other studies did not demonstrate systemic blood pressure reduction during NO inhalation, suggesting that the NO effect is local on the lung vasculature, presumably because $\mathrm{NO}$ is inactivated by reaction with oxyhemoglobin to form methemoglobin and nitrate. Consistent with these findings, we saw minimal effects of NO inhalation on forearm blood flow, vascular resistance, or blood pressure under physiological conditions of local synthesis of NO by the endothelium of the forearm vasculature. The absence of local vasodilation in response to inhaled NO suggests that in healthy vasculature, synthesis of $\mathrm{NO}$ by the endothelium masks any contribution of intravascular-transported NO.

However, we found that when endothelial NO synthesis was pharmacologically inhibited by an L-NMMA infusion, inhaled NO exhibited potent vasoactive effects, restoring blood flow and vascular resistance toward basal levels. Furthermore, exercise performed during forearm inhibition of endothelial NO synthesis was associated with greater vasodilation during $\mathrm{NO}$ breathing compared with room air breathing, with metabolic evidence of improved tissue perfusion. This finding suggests a significant contribution of $\mathrm{NO}$ to exercise-induced vasodilation and is consistent with the observation of reduced forearm blood flow with forearm exercise after regional blockade of NO synthase reported by Gilligan et al. (30). Accordingly, in experimental (and potentially pathophysiological) conditions associated with reduced regional endothelial synthesis and release of $\mathrm{NO}$, transport of $\mathrm{NO}$ from the lungs to the peripheral circulation may assume physiological importance. These data provide, to our knowledge, the first evidence for the intravascular delivery of bioactive NO species in humans and suggest that inhaled NO may have application for the treatment of diseases characterized by reduced regional NO production, such as peripheral vascular disease and coronary artery disease caused by atherosclerosis $(8,9,31)$. Because the effects of $\mathrm{NO}$ breathing on vasculature constricted by other agonists (e.g., phenylephrine) with regional NO synthesis intact was not determined in our study, we cannot be certain that the vascular effects of inhaled NO are specific to deficient regional NO synthesis. However, a vasodilator effect of NO breathing in vascular territories constricted by circulating or locally synthesized agonists despite intact regional NO synthesis could broaden the therapeutic potential of NO inhalation and deserves further study.
These results are consistent with recent models of intravascular biostabilization and delivery of $\mathrm{NO}$ (10-15). While SNO-Hb levels are not significantly higher during NO breathing compared with basal levels, nitrosyl(heme)hemoglobin levels rose tenfold with a significant artery-to-vein gradient, suggesting NO metabolism and/or delivery. Additionally, arterial nitrite levels increased, albeit to a lesser extent, with significant artery-to-vein gradients. The observed regional vasodilation during $\mathrm{NO}$ breathing when local synthesis of NO was inhibited could therefore be mediated by NO released by nitrosyl(heme)hemoglobin, directly or via a SNO-Hb intermediate, or by nitrite bioconversion to NO.

Consistent with the high affinity of NO for heme groups (Ka of $10^{7} \mathrm{M}^{-1} \mathrm{~s}^{-1}$ ), our work suggests that during NO breathing limited S-nitrosothiol formation occurs while reactions with heme groups lead to large increases in nitrosylated hemoglobin. However, in sharp contrast with in vitro observations of the slow off-rate of NO from hemoglobin iron groups (32), the half-life of nitrosyl(heme)hemoglobin in vivo is considerably less, with greater than $20 \%$ measured decrease in the nitrosyl(heme)hemoglobin concentration from artery to vein (approximately 10-30 seconds, assuming 60 seconds for red cell circulation). Such results could be explained by rapid metabolism of the nitrosyl(heme)hemoglobin to nitrate, release of NO from heme to thiol groups (via intraerythrocytic glutathione to form S-nitrosoglutathione or hemoglobin $\beta$-chain cysteine-93 to form a SNO-Hb intermediate), or via the release of NO directly from the heme group of deoxygenated hemoglobin with diffusion in the gaseous state to the vasculature.

From a biochemical standpoint, vasodilation mediated by NO released from nitrosyl(heme)hemoglobin is thought to be limited by the rapid reactions between $\mathrm{NO}$ and both oxygenated and deoxygenated hemoglobin. However, there exist mechanisms to accelerate the release of $\mathrm{NO}$ from the heme group in regions with low oxygen tension which exist even in resting muscular tone. This release is possible because in vivo, on average, only one NO molecule would be expected to be bound to a hemoglobin tetramer because of its very low concentration, with the remaining heme groups carrying oxygen. With extensive deoxygenation in regions of low oxygen tension, the hemoglobin structural transition to the $\mathrm{T}$ state would destabilize the remaining NO ligand. The dissociation rate constants for $\mathrm{NO}$ are accelerated by at least two orders of magnitude with the R-to-T transition $\left[10^{-4}\right.$ to $10^{-5} \mathrm{~s}^{-1}$ for $\mathrm{R}$ state $\left(\mathrm{Hb}_{4}\left(\mathrm{O}_{2}\right)_{3} \mathrm{NO}\right)$ and $10^{-2}$ to $10^{-3} \mathrm{~s}^{-1}$ for $\mathrm{T}$ state $\left.\left(\mathrm{Hb}_{4} \mathrm{NO}\right)\right](32,33)$. This rate is further accelerated by heterotropic effectors, such as protons and 2,3-diphosphoglycerate, with dissociation accelerating to seconds $(34,35)$.

Assuming a dissociation constant of 0.01 , the halflife of nitrosyl(heme)hemoglobin would be approximately 60 seconds, potentially allowing significant 


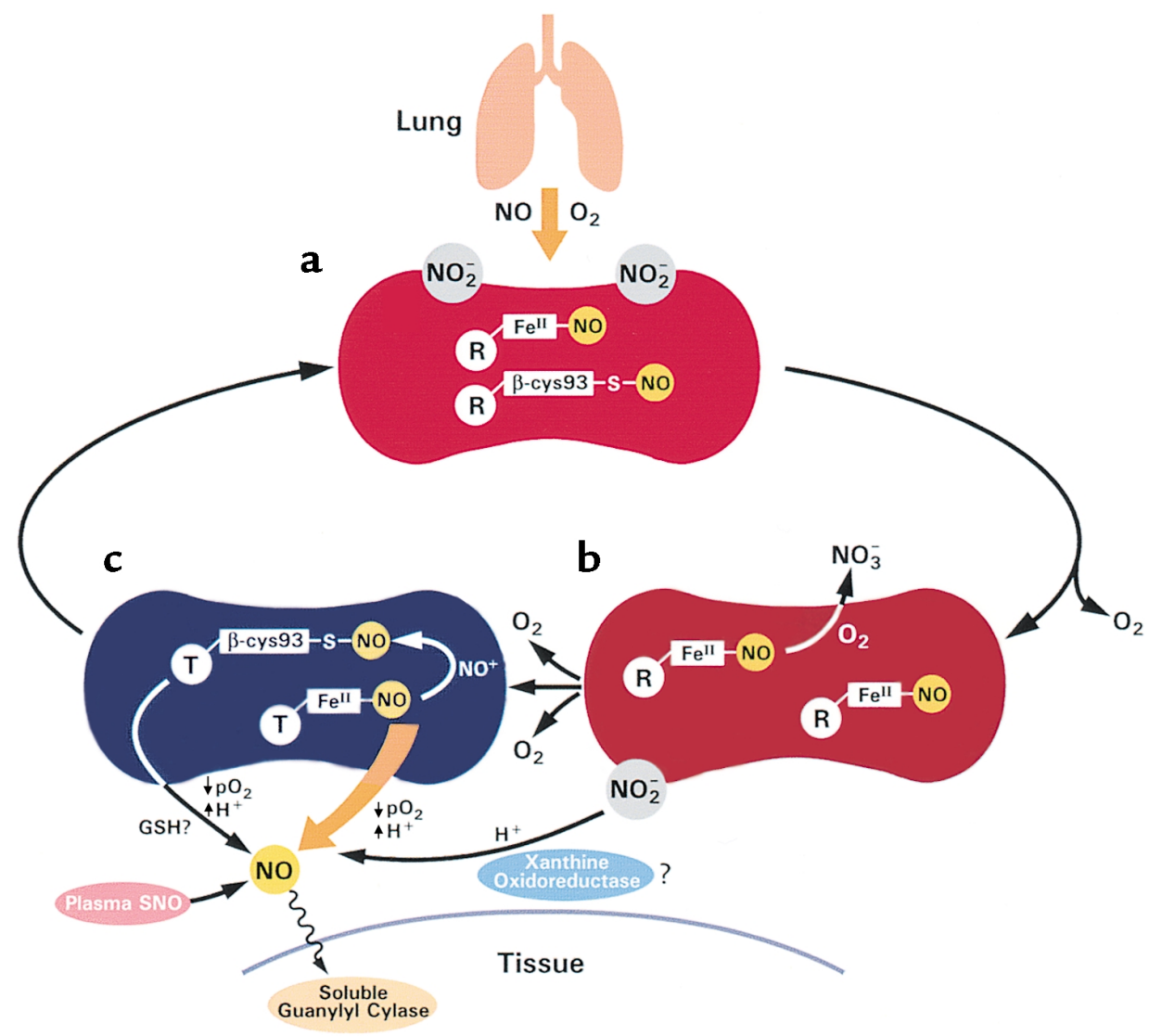

Figure 6

A model of the mechanism of vascular transport of bioactive NO by red cells and plasma during NO inhalation (based on refs. 11-15). (a) During $\mathrm{NO}$ inhalation, $\mathrm{NO}$ and oxygen in the pulmonary vasculature react to form nitrite $\left(\mathrm{NO}_{2}^{-}\right)$. $\mathrm{NO}$ also binds to deoxyheme groups of hemoglobin to form nitrosyl(heme)hemoglobin (Fe"l-NO) and possibly with oxyhemoglobin $\beta$-globin cysteine-93 to form S-nitrosohemoglobin ( $\beta$-cys93-S-NO). The major reaction of $\mathrm{NO}$ with oxyhemoglobin to form methemoglobin and nitrate $\left(\mathrm{NO}_{3}^{-}\right)$is not shown here but accounts for the rise of methemoglobin from approximately $0.2 \%$ to $1 \%$ during NO inhalation. (b) In the partially deoxygenated red cell some $\mathrm{NO}$ of nitrosyl(heme)hemoglobin will react with oxygen or with oxyhemoglobin to form nitrate and methemoglobin. (c) When hemoglobin saturation and tissue $\mathrm{pO}_{2}$ are very low, these reactions are significantly reduced and $\mathrm{NO}$ release from the red cell becomes possible. The hemoglobin structural transition from the oxy-state $(R)$ to the deoxy-state $(T)$ destabilizes the remaining NO ligand. This rate is further accelerated by heterotropic effectors, such as protons and 2,3-diphosphoglycerate, and requires a high-affinity acceptor for NO. It is possible that transfer of $\mathrm{NO}(\mathrm{NO}+)$ from heme to the hemoglobin $\beta$-chain cysteine-93 occurs to form a S-nitrosohemoglobin intermediate that then releases $\mathrm{NO}$ by transnitrosation with glutathione (GSH). In addition, plasma nitrite may be converted to NO by disproportionation or by metal- or enzyme-catalyzed (xanthine oxidoreductase) processes. Finally, plasma S-nitrosothiol proteins could bind and deliver NO. Most of these pathways will occur preferentially in regions with low $\mathrm{O}_{2}$ tension and $\mathrm{pH}$, resulting in delivery of $\mathrm{NO}$ to these sites.

dissociation of $\mathrm{NO}$ in the 10 - to 30 -second circulatory time from artery to vein. The biochemical fate of the NO released depends critically on it not reacting with oxyhemoglobin to form bioinactive nitrate. When hemoglobin saturation and tissue $\mathrm{pO}_{2}$ are low (10-25\% oxyhemoglobin saturation and tissue $\mathrm{pO}_{2}$ of $0-14 \mathrm{mmHg}$ in metabolizing tissue $(36,37)$, these reactions are significantly reduced, and NO release from the red cell becomes possible. This release requires a high-affinity acceptor; however, potential high-affinity acceptors are ubiquitous in endothelium (soluble guanylyl cyclase), smooth and striated muscle (myoglobin), and brain (neuroglobin). Even if less than $1 \%$ of our observed artery-to-vein gradients in nitrosyl(heme)-hemoglobin during NO breathing $(176,468$, and $340 \mathrm{nM} \mathrm{NO}$ at baseline, L-NMMA and exercise, respectively) were released and escaped reac- tion with oxygen and oxyhemoglobin, this would result in vasodilation. In this regard, the concentration of NO required to achieve $50 \%$ relaxation of aortic ring bioassays $\left(\mathrm{EC}_{50}\right)$ is approximately $5 \mathrm{nM}(38)$. Furthermore, L-NMMA treatment (and eNOS knockout) potentiates the sensitivity of soluble guanylyl cyclase to $\mathrm{NO}$, resulting in an $\mathrm{EC}_{50}$ of less than $1 \mathrm{nM}$ NO concentration.

Our observed artery-to-vein gradients in nitrosyl(heme)hemoglobin during NO breathing and the associated blood flow effects suggest the possibility that other high-affinity ligands may be delivered by hemoglobin. In fact, carbon monoxide (CO) exists bound to hemoglobin in concentrations of $0.3-1 \%$ (30 $\mu \mathrm{M}$ to $100 \mu \mathrm{M}$ ) and has been found to participate in blood flow regulation and cell-signaling pathways, with distal effects observed during $\mathrm{CO}$ inhalation 
(39-41). Published data suggest that direct allosteric (oxygen-linked) release of $\mathrm{CO}$ from hemoglobin during regional hypoxia $(42)$ and exercise $(43,44)$ occurs and is consistent with CO delivery from hemoglobin. These experiments further support the notion that highaffinity gas ligands, including NO, may be released from hemoglobin to the tissues, particularly in hypoxic or relatively acidic vascular beds.

We did not observe an increase in HMW-SNO (SNOalbumin) during NO breathing, suggesting that plasma SNO compounds do not mediate the observed blood flow effect. However, recent data suggest that the SNO-albumin is unstable in plasma due to its breakdown in the presence of low-molecular-weight thiols (45). While the rapid separation of the albumin from the low-molecular-weight thiol pool (as we did in this study) will conserve the HMW-SNO, it remains possible that an increase in HMW-SNO did occur during NO breathing that we failed to detect. Newer methodologies to preserve plasma S-nitrosothiols are required to answer this question.

While the nitrite concentration only increased by approximately $90 \mathrm{nM}$, such a sustained increase over 1 hour could also potentially contribute to the peripheral effects of NO inhalation. Unlike nitrate, which is thought to be a biologically inactive endproduct of NO reactions with oxyhemoglobin, recent data suggest that nitrite remains bioactive. We have reported recently baseline arterial-venous nitrite gradients in normal human volunteers, providing a potential delivery source for intravascularly produced NO (11). Under physiologic levels of acidity, nitrite forms nitrous acid, which can react with nitrite again to form $\mathrm{N}_{2} \mathrm{O}_{3}$. This reactive nitrogen species can nitrosate thiols (which are vasoactive) or in the presence of an electron donor produce NO (46). NO generation has been documented in ischemic myocardi$\mathrm{um}$; this requires low tissue $\mathrm{pH}$, tissue reductants, and/or nitrite disproportionation $(47,48)$. Alternatively, this conversion could be metal or enzyme catalyzed. For example, recent studies suggest that xanthine oxidoreductase, which is present in abundance in vascular endothelium, may reduce nitrite to $\mathrm{NO}$, an effect that increases with decreasing $\mathrm{pH}$, increasing NADH concentration, and hypoxia (49-51). By either mechanism, under acidic conditions potentially associated with stress such as reduced blood flow or exercise, the conversion of nitrite to NO could also potentially augment regional blood flow and oxygen delivery. Further experimental work in animal models and in humans will be required to determine the biological relevance of these potential mechanisms. A schematic model of these proposed mechanisms for red cell and plasma transport of NO is shown in Figure 6.

In recent years, there has been increasing evidence for depressed bioavailability of $\mathrm{NO}$ in syndromes associated with atherosclerosis and its risk factors, with defects in both basal and pharmacologically stimulated endothelial NO production reported $(8,9,31)$. Our observation that NO inhalation results in peripheral vasodilation targeted to regions with pharmacologically reduced NO production may have therapeutic applications in diseases characterized by regional $\mathrm{NO}$ deficiency. The most fundamental and important observation of this study is that NO gas introduced to the lungs can be stabilized and transported in blood and peripherally modulate blood flow.

\section{Acknowledgments}

We would like to thank James S. Nichols, William H. Schenke, Melissa Bryant, Wynona Coles, and the Critical Care Therapy and Respiratory Care Section of the Critical Care Medicine Department for their considerable help with this study.

1. Furchgott, R.F., and Zawadzki, J.V. 1980. The obligatory role of endothelial cells in the relaxation of arterial smooth muscle by acetylcholine. Nature. 288:373-376.

2. Ignarro, L.J., Byrns, R.E., Buga, G.M., and Wood, K.S. 1987. Endothelium-derived relaxing factor from pulmonary artery and vein possesses pharmacologic and chemical properties identical to those of nitric oxide radical. Circ. Res. 61:866-879.

3. Palmer, R.M., Ferrige, A.G., and Moncada, S. 1987. Nitric oxide release accounts for the biological activity of endothelium-derived relaxing factor. Nature. 327:524-526.

4. Palmer, R.M., Ashton, D.S., and Moncada, S. 1988. Vascular endothelial cells synthesize nitric oxide from L-arginine. Nature. 333:664-666.

5. Rees, D.D., Palmer, R.M., Hodson, H.F., and Moncada, S. 1989. A specific inhibitor of nitric oxide formation from $\mathrm{L}$-arginine attenuates endothelium-dependent relaxation. Br. J. Pharmacol. 96:418-424.

6. Amezcua, J.L., Palmer, R.M., de Souza, B.M., and Moncada, S. 1989. Nitric oxide synthesized from L-arginine regulates vascular tone in the coronary circulation of the rabbit. Br. J. Pharmacol. 97:1119-1124.

7. Chu, A., et al. 1991. Effects of inhibition of nitric oxide formation on basal vasomotion and endothelium-dependent responses of the coronary arteries in awake dogs. J. Clin. Invest. 87:1964-1968.

8. Panza, J.A., Casino, P.R., Kilcoyne, C.M., and Quyyumi, A.A. 1993. Role of endothelium-derived nitric oxide in the abnormal endotheliumdependent vascular relaxation of patients with essential hypertension. Circulation. 87:1468-1474.

9. Quyyumi, A.A., et al. 1995. Nitric oxide activity in the human coronary circulation. Impact of risk factors for coronary atherosclerosis. J. Clin. Invest. 95:1747-1755.

10. Stamler, J.S., et al. 1992. Nitric oxide circulates in mammalian plasma primarily as an S-nitroso adduct of serum albumin. Proc. Natl. Acad. Sci. USA. 89:7674-7677.

11. Gladwin, M.T., et al. 2000. Role of circulating nitrite and S-nitrosohemoglobin in the regulation of regional blood flow in humans. Proc. Natl. Acad. Sci. USA. 97:11482-11487.

12. Jia, L., Bonaventura, C., Bonaventura, J., Stamler, J.S. 1996. S-nitrosohaemoglobin: a dynamic activity of blood involved in vascular control. Nature. 380:221-226.

13. Stamler, J.S., et al. Blood flow regulation by S-nitrosohemoglobin in the physiological oxygen gradient. 1997. Science. 276:2034-2037.

14. Gow, A.J., and Stamler, J.S. 1998. Reactions between nitric oxide and haemoglobin under physiological conditions. Nature. 391:169-173.

15. Gladwin, M.T., et al. 2000. Relative role of heme nitrosylation and betacysteine 93 nitrosation in the transport and metabolism of nitric oxide by hemoglobin in the human circulation. Proc. Natl. Acad. Sci. USA. 97:9943-9948.

16. Takahashi, Y., et al. 1998. Nitrosyl hemoglobin in blood of normoxic and hypoxic sheep during nitric oxide inhalation. Am. J. Physiol. 274:H349-H357.

17. Troncy, E., et al. 1997. Extra-pulmonary effects of inhaled nitric oxide in swine with and without phenylephrine. Br. J. Anaesth. 79:631-640.

18. Kermarrec, N., et al. 1998. Impact of inhaled nitric oxide on platelet aggregation and fibrinolysis in rats with endotoxic lung injury. Role of cyclic guanosine 5'- monophosphate. Am. J. Respir. Crit. Care Med. 158:833-839.

19. Fox-Robichaud, A., et al. 1998. Inhaled NO as a viable antiadhesive therapy for ischemia/reperfusion injury of distal microvascular beds. J. Clin. Invest. 101:2497-2505.

20. Kubes, P., Payne, D., Grisham, M.B., Jourd-Heuil, D., and Fox- 
Robichaud, A. 1999. Inhaled NO impacts vascular but not extravascular compartments in postischemic peripheral organs. Am. J. Physiol. 277:H676-H682.

21. Gladwin, M.T., et al. 1999. Inhaled nitric oxide augments nitric oxide transport on sickle cell hemoglobin without affecting oxygen affinity. $J$. Clin. Invest. 104:937-945.

22. Winterbourn, C.W. 1990. Oxidative reactions of hemoglobin. Methods Enzymol. 186:265-272.

23. Samouilov, A., and Zweier, J.L. 1998. Development of chemiluminescence-based methods for specific quantitation of nitrosylated thiols. Anal. Biochem. 258:322-330.

24. Ewing, J.F., and Janero, D.R. 1998. Specific S-nitrosothiol (thionitrite) quantification as solution nitrite after vanadium(III) reduction and ozone-chemiluminescent detection. Free Radic. Biol. Med. 25:621-628.

25. Fang, K., Ragsdale, N.V., Carey, R.M., MacDonald, T., and Gaston, B. 1998. Reductive assays for S-nitrosothiols: implications for measurements in biological systems. Biochem. Biophys. Res. Commun 252:535-540.

26. Frostell, C., Fratacci, M.D., Wain, J.C., Jones, R., and Zapol, W.M. 1991. Inhaled nitric oxide. A selective pulmonary vasodilator reversing hypoxic pulmonary vasoconstriction. Circulation. 83:2038-2047.

27. Rossaint, R., et al. 1993. Inhaled nitric oxide for the adult respiratory distress syndrome. N. Engl. J. Med. 328:399-405.

28. Roberts, J.D., Jr., et al. 1997. Inhaled nitric oxide and persistent pulmonary hypertension of the newborn. The inhaled nitric oxide study group. N. Engl. J. Med. 336:605-610.

29. Troncy, E., et al. 1998. Inhaled nitric oxide in acute respiratory distress syndrome: a pilot randomized controlled study. Am. J. Respir. Crit. Care Med. 157:1483-1488.

30. Gilligan, D.M., et al. 1994. Contribution of endothelium-derived nitric oxide to exercise-induced vasodilation. Circulation. 90:2853-2858.

31. Ludmer, P.L., et al. 1986. Paradoxical vasoconstriction induced by acetylcholine in atherosclerotic coronary arteries. N. Engl. J. Med. 315:1046-1051.

32. Cooper, C.E. 1999. Nitric oxide and iron proteins. Biochim. Biophys. Acta. 1411:290-309.

33. Moore, E.G., and Gibson, Q.H. 1976. Cooperativity in the dissociation of nitric oxide from hemoglobin. J. Biol. Chem. 251:2788-2794.

34. Hlastala, M.P., McKenna, H.P., Franada, R.L., and Detter, J.C. 1976. Influence of carbon monoxide on hemoglobin-oxygen binding. J. Appl. Physiol. 41:893-899.

35. Coletta, M., et al. 1999. Heterotropic effectors exert more significant strain on monoligated than on unligated hemoglobin. Biophys. $J$ 76:1532-1536

36. Zheng, L., Golub, A.S., and Pittman, R.N. 1996. Determination of PO2 and its heterogeneity in single capillaries. Am. J. Physiol. 271:H365-H372. 37. Liss, A.G., and Liss, P. 2000 . Use of a modified oxygen microelectrode and laser-Doppler flowmetry to monitor changes in oxygen tension and microcirculation in a flap. Plast. Reconstr. Surg. 105:2072-2078.

38. Brandes, R.P., et al. 2000. Increased nitrovasodilator sensitivity in endothelial nitric oxide synthase knockout mice: role of soluble guanylyl cyclase. Hypertension. 35:231-236.

39. Gutierrez, G., Rotman, H.H., Reid, C.M., and Dantzker, D.R. 1985. Comparison of canine cardiovascular response to inhaled and intraperitoneally infused CO. J. Appl. Physiol. 58:558-563.

40. Shimazu, T., et al. 2000. Half-life of blood carboxyhemoglobin after shortterm and long-term exposure to carbon monoxide. J. Trauma. 49:126-131.

41. Otterbein, L.E., et al. 2000. Carbon monoxide has anti-inflammatory effects involving the mitogen-activated protein kinase pathway. Nat. Med. 6:422-428.

42. Coburn, R.F., and Mayers, L.B. 1971. Myoglobin O2 tension determined from measurement of carboxymyoglobin in skeletal muscle. Am. J. Physiol. 220:66-74.

43. Werner, B., and Lindahl, J. 1980. Endogenous carbon monoxide production after bicycle exercise in healthy subjects and in patients with hereditary spherocytosis. Scand. J. Clin. Lab. Invest. 40:319-324.

44. Sokal, J., Majka, J., and Palus, J. 1986. Effect of work load on the content of carboxymyoglobin in the heart and skeletal muscles of rats exposed to carbon monoxide. J. Hyg. Epidemiol. Microbiol. Immunol. 30:57-62.

45. Jourd'heuil, D., Hallen, K., Feelisch, M., and Grisham, M.B. 2000. Dynamic state of S-nitrosothiols in human plasma and whole blood. Free Radic. Biol. Med. 28:409-417.

46. Zweier, J.L., Wang, P., Samouilov, A., and Kuppusamy, P. 1995. Enzymeindependent formation of nitric oxide in biological tissues. Nat. Med. 1:804-809.

47. Samouilov, A., Kuppusamy, P., and Zweier, J.L. 1998. Evaluation of the magnitude and rate of nitric oxide production from nitrite in biological systems. Arch. Biochem. Biophys. 357:1-7.

48. Zweier, J.L., Samouilov, A., and Kuppusamy, P. 1999. Non-enzymatic nitric oxide synthesis in biological systems. Biochim. Biophys. Acta. 1411:250-262.

49. Millar, T.M., et al. 1998. Xanthine oxidoreductase catalyses the reduction of nitrates and nitrite to nitric oxide under hypoxic conditions. FEBS Lett. 427:225-228.

50. Zhang, Z., et al. 1998. Generation of nitric oxide by a nitrite reductase activity of xanthine oxidase: a potential pathway for nitric oxide formation in the absence of nitric oxide synthase activity. Biochem. Biophys. Res. Commun. 249:767-772.

51. Godber, B.L., et al. 2000. Reduction of nitrite to nitric oxide catalyzed by xanthine oxidoreductase. J. Biol. Chem. 275:7757-7763. 